\title{
Eenowaral \\ Tacking GI emergencies in India means and ways to improve it?
}

\author{
Usha Dutta, Deepak Gunjan
}

\section{Introduction}

Department of Gastroenterology, Postgraduate Institute of Medical Education and Research, Chandigarh -160012

\section{Correspondence:}

Dr. Usha Dutta,

Email: ushadutta@gmail.com
Gastrointestinal emergencies constitute a huge clinical and economic burden in various emergency units all round the world. They constitute $12 \%$ of all the emergency visits and are associated with a mortality of over $10 \%{ }^{1}$ They are a result of either underlying significant life threatening inflammation, infection, ischemia, vascular lesions, obstruction or perforation of the GI tract. They often present in the emergency setting with superadded septicaemia / shock / organ failure. Gastrointestinal (GI) emergencies like other emergencies require time critical interventions to minimize morbidity and mortality. In contrast to other emergencies, it requires multidisciplinary approach involving gastroenterologists, radiologists, surgeons and critical care specialists. They also result in higher hospitalization rates compared to those presenting with non-GI problems ( $21.6 \%$ vs $14 \%) .{ }^{1}$ In contrast to cardiac and neurological emergencies, managing most GI emergencies require relatively low cost interventions which are life saving. Cardiologists and neurologists have gone a long way in improving the structure and processes in managing the two of their common life threatening emergencies namely myocardial infarction and stroke., ${ }^{2,3}$ They have also strived to improve public awareness of these conditions resulting in making them partners in the process of emergency care delivery. Gastroenterologists still have to take these issues head on. Quality improvement studies are severely lacking in the field of gastrointestinal emergencies and usually pertain to only managing endoscopy services in patients with GI bleeding. ${ }^{4-6}$

\section{Managing emergencies: Global Vs Indian perspective}

Emergency rooms all around the world are always busy, overflowing, resource intensive areas of the hospital where supply always falls short of demand. In India, in addition, we have a huge health care burden, lack of public awareness, difficulties in transport, poor health care resources, lack of structured referral system, poor doctor-patient ratio, lack of standardized health care, lack of medical audits, constraints due to payment of expenses out-of-the-pocket, resulting in an overall poor emergency health care delivery.-9 In India, due to poor health awareness, patients present for the first time to the emergency setup of the hospital with complications of their underlying disease, the nature of which has remained undiagnosed until then. This makes it even more difficult for the treating doctor to establish the primary diagnosis as well as deal with the superadded complication simultaneously. Patients have to travel long distances to reach tertiary care centers, further worsening their clinical condition. ${ }^{9}$ Poor organization of facilities at the tertiary care centre, high patient load, lack of structured flow only compounds their problem further. 
All over the world, the first contact physician is often a junior level doctor, who is still under training and delivers care in consultation with his senior colleagues. They are often not fully trained to deal with emergencies independently and sometimes unable to deliver effective care given the complexity of the situation. Crucial time is lost in the resident physician consulting his seniors or accessing medical literature. Random accessing of medical literature in an unstructured fashion may be time consuming/ inadequate and misleading. These issues result in loss of crucial time for initiation of appropriate care of the patient. It is neither practical nor cost effective to ensure an availability of a senior physician round the clock to run the emergency services Thus, we need standard protocols prepared by senior physicians to assist the last standing man in delivering effective and efficient care.

\section{Evidence based medicine in emergency care}

The field of medicine revolves around putting existing knowledge into action in the best interest of the patient. The field of knowledge translation pertains to bridging barriers in order to bring the existing knowledge into action. ${ }^{11}$ Large amount of time and resources are spent on creating evidence-based guidelines. They are usually published in textbooks, society guidelines and manuals. They take time for this knowledge to percolate to each and every treating physician and thus do not end up benefitting each and every patient for whom it was intended. ${ }^{10-12}$ This vast gap is due to the practical difficulties for the treating doctor in quickly and effectively accessing these resources. The guidelines also keep changing with time and it is impractical for each physician to be abreast with all the latest guidelines. Various emergency departments have thus created customized protocols for managing emergency situation in their setup. These are usually in a printed format and available as a manual. However, they are difficult to update, bulky to access and may be not easily traceable. There is thus a felt need to provide evidence based information in an easily accessible and updatable format to the treating physician at the bedside of the patient.

\section{Mobile apps in medicine}

Mobile apps are software programs that run on smart phones and other mobile communication devices. These are tools to assist health care professionals in health care delivery. They can also assist the patients in obtaining required medical information, accessing medical care and help them in maintain their treatment schedule. These tools are very popular and get adopted almost as quickly as they are developed. It is estimated that by 2018,50 percent of the 3.4 billion smart phone/ tablet users will have downloaded mobile health applications. ${ }^{13}$ They can be used to enter patient data, calculate various scores, access medical resources, or double up as medical equipment (electronic stethoscope, an ECG monitor, pulse oximeter, fundoscope, etc). Increasingly, various decision support tools are available in an app format to assist clinicians on the bedside (Table 1). These decision support tools have been shown to improve resident training as well as patient related outcomes. ${ }^{14-16}$ It is likely to empower the treating doctor as well as enhance the quality and efficiency of his/ her performance.

Table 1 : Interventions to improve emergency care in India.

\begin{tabular}{|c|c|}
\hline Level & Interventions \\
\hline Patient & $\begin{array}{l}\text { - Education about disease condition } \\
\text { - Prevention of anticipated complications } \\
\text { - Recognition of danger signs } \\
\text { - Health card to state diagnosis and outline } \\
\text { management of anticipated complications for } \\
\text { the primary care physician. }\end{array}$ \\
\hline Transport & $\begin{array}{l}\text { - Advice regarding choice of residence vis-a-vis } \\
\text { health care system } \\
\text { - Availability of ambulance services }\end{array}$ \\
\hline Resident & $\begin{array}{l}\text { - Preliminary training before being put on duty } \\
\text { - Accessible resources for consultation }\end{array}$ \\
\hline Consultant & $\begin{array}{l}\text { - Provide active supervision } \\
\text { - Standardizing health care delivery through } \\
\text { protocols and training } \\
\text { - Being up to date with latest guidelines } \\
\text { - Organizing emergency services } \\
\text { - Ensuring availability of protected time for the } \\
\text { emergency team }\end{array}$ \\
\hline Institutional & $\begin{array}{l}\text { - A GI Helpline. Triage system } \\
\text { - Training of health care personnel } \\
\text { - Ensuring availability of GI emergency kit } \\
\text { (Table 2) } \\
\text { - Organizing multidisciplinary teams } \\
\text { - Improving soft skills of health care personnel } \\
\text { - Allocation of funding for emergency care } \\
\text { - Hospital audits. Promote research on quality } \\
\text { of health care delivery issues }\end{array}$ \\
\hline National Level & $\begin{array}{l}\text { - Infrastructure development } \\
\text { - Public awareness about diseases } \\
\text { - Improving health care funding } \\
\text { - Training of primary care physicians }\end{array}$ \\
\hline
\end{tabular}




\section{GI-Liver emergencies app}

In India, most of the trainee physicians possess smart phones. A smart app which can provide the necessary information for managing common GI emergencies on their finger tips can enhance patient care and as well provide training. ${ }^{15,17} \mathrm{We}$, at PGIMER Chandigarh, recently designed a GI liver mobile app to provide a decision support tool for managing 15 common GI liver emergencies. It has been made in a user friendly, intuitive, easily navigatable colour coded actionable format. The assessment and management of each emergency is provided under the sections of diagnosis, investigations, severity assessment and management. The contents of this app were deliberated upon by the team and were subsequently vetted by national experts. The utility of it in clinical scenarios was validated by a study conducted among resident doctors $(n=42)$ in PGIMER, Chandigarh found that it enhanced their mean performance scores from 57 to 71 in simulated conditions $(\mathrm{p}<0.001)$. This app was launched at the midterm ISG meeting in Delhi and is now freely downloadable from the website (www.pgimer.edu.in). The feedback has been overwhelmingly positive and over 1400 physicians have already downloaded it. We feel that apps like these are likely to reduce time to decision making, reduce duration of stay in the emergency area and improve overall patient outcomes. However, further studies to assess its efficacy in real life scenario needs to be conducted.

\section{What are the downsides of using apps}

Decisions taken independently by a junior physician based on decision support tools runs the risk of judgment errors. Certain clinical care decisions can be only taken at the bedside by a senior physician in the context of an index patient. Also, an algorithmic approach to managing patients without understanding the science behind it is fraught with problems related to the superficial understanding of medical science. Medical mobile apps usually are prepared by medical experts in conjunction with software experts. They may sometimes lack rigorous and formal peer review of its contents. Care must be also taken as some apps may contain outdated information. Most of these apps are not evaluated by a regulatory body before release. FDA regulates only those apps which could pose some risk to patient's safety if the app does not function as intended. ${ }^{18}$ Apps which pose a low risk are under the enforcement discretion of FDA. Many apps that masquerade as medical apps may not meet the stringent requirements and due caution needs to be exercised. Medical mobile apps need to cross a higher threshold of accuracy, as the consequences of inaccuracy may be life threatening.

\section{How can we improve the management of GI Emergencies in India?}

Understanding the gaps and barriers in the existing system is necessary before planning any intervention. Though various interventions have been found useful, interventions at organization, physician and patient level are most likely to be rewarding (Table 2). They however, need to be customized for each medical centre. Introduction of multiple quality improvement measures is more effective than introduction of a single measure. The emergency set up needs to have a designated GI corner where equipments and resources for managing GI emergencies can be easily accessed (Table 3). Clubbing of all GI patients in one corner will also facilitate consultations from treating specialists as they can track their patients easily. A pre-designated time for a multidisciplinary team, to meet and discuss the patient's needs on the bedside will facilitate rapid coordinated delivery of care. Availability of endoscopic and radiological services is necessary to perform life saving diagnostic and therapeutic interventions. Emergency endoscopy room should have standard equipments, trained assistants with availability of required accessories and medications. ${ }^{14}$ Emergency endoscopy service should be provided preferably as the first activity in the morning of all days including weekends, if required. Most patients presenting

Table 2: Recommended list of common medications and accessories required for managing GI emergencies

- Inj. Dextrose 25\%

- Inj. Mannitol

- Inj. Albumin

- Inj. Terlipressin

- Inj. Octreotide

- Inj. Vitamin K

- Inj. Proton pump inhibitors

- Inj. N-acetyl cysteine

- Inj. Diclofenac/tramadol/morphine

- Inj. Lorazepam / Oxazepam

- Inj. Levetiracetam)

- Syp. Lactulose

- Anti-emetics and pro-kinetics

- Ryles' tube

- Sengstaken-Blakemore tube withanchoring devices, artery forceps and scissors 
Table 3: Common mobile apps for Gastroenterologists

\begin{tabular}{|c|c|c|c|}
\hline Apps Name & Key features & Web-address & Free/Paid \\
\hline iLiver & Information on various liver diseases from EASL & www.iliver.eu & Free \\
\hline EASL's Liver Tree & $\begin{array}{l}\text { Access to provide webcasts, e-posters, videos, } \\
\text { abstracts by leading experts on liver diseases }\end{array}$ & $\begin{array}{l}\text { http://www.easl.eu/research/training } \\
\text {-the-liver-study/easl-educational- } \\
\text { tools/livertree }\end{array}$ & Free \\
\hline $\begin{array}{l}\text { Surgical Anatomy of } \\
\text { the Liver }\end{array}$ & $\begin{array}{l}\text { Teaching and training tool to understand 3D } \\
\text { anatomy of liver }\end{array}$ & $\begin{array}{l}\text { http://medapps.emory.edu/surgical- } \\
\text { anatomy-of-the-liver/ }\end{array}$ & Free \\
\hline Stroop app & Minimal hepatic encephalopathy assessment & http://www.encephalapp.com & Free \\
\hline My Liver App & $\begin{array}{l}\text { To explain complex medical conditions to families } \\
\text { and kids using easy language and illustrations }\end{array}$ & $\begin{array}{l}\text { http://pediatricliver.ca/for-parents- } \\
\text { and-families/learning-centre/my- } \\
\text { liver-app/ }\end{array}$ & Free \\
\hline GI Liver App & $\begin{array}{l}\text { Decision support tool for doctors handling GI and } \\
\text { Liver emergencies }\end{array}$ & http://pgimer.edu.in & Free \\
\hline QxMD & $\begin{array}{l}\text { Medical calculator and decision support tool for } \\
\text { doctors }\end{array}$ & $\begin{array}{l}\text { http://www.qxmd.com/specialty/ } \\
\text { medicine/gastroenterology-medical- } \\
\text { apps-iphone-blackberry-android }\end{array}$ & Free \\
\hline Read by QxMD & $\begin{array}{l}\text { Provides access to new research, topic reviews } \\
\text { and searching PubMed }\end{array}$ & $\begin{array}{l}\text { http://www.qxmd.com/apps/read-by- } \\
\text { qxmd-app }\end{array}$ & Free \\
\hline Epocrates & Review drug prescribing and safety information & $\begin{array}{l}\text { http://www.epocrates.com/products/ } \\
\text { iphone/rxpro.html }\end{array}$ & Free \\
\hline $\begin{array}{l}\text { Low FODMAP } \\
\text { smartphone app }\end{array}$ & $\begin{array}{l}\text { FODMAP content of foods and information on } \\
\text { low FODMAP diets }\end{array}$ & $\begin{array}{l}\text { http://www.med.monash.edu.au/cecs/ } \\
\text { gastro/fodmap/iphone-app.html }\end{array}$ & Paid \\
\hline $\begin{array}{l}\text { Digestive disease and } \\
\text { liver app }\end{array}$ & $\begin{array}{l}\text { Read the journal contents of Digestive and Liver } \\
\text { Disease }\end{array}$ & $\begin{array}{l}\text { https://itunes.apple.com/in/app/ } \\
\text { digestive-and-liver-disease }\end{array}$ & Paid \\
\hline Upto date & $\begin{array}{l}\text { Clinical decision support resource with evidence- } \\
\text { based clinical information }\end{array}$ & $\begin{array}{l}\text { https://play.google.com/store/apps/ } \\
\text { details?id=com.uptodate }\end{array}$ & Paid \\
\hline Pocket Lab values & Laboratory values and the causes for abnormal values & $\begin{array}{l}\text { https://play.google.com/store/apps/ } \\
\text { details?id=com.medplusapps.pocketlab } \\
\text { values }\end{array}$ & Paid \\
\hline
\end{tabular}

with GI bleed or cholangitis require stabilization followed by endoscopy within the first 12-24 hours. Only bleeders with ongoing bleed or those who are hemodynamically unstable need immediate access to endoscopy services. ${ }^{15}$ Most of the quality improvement studies in GI emergencies have focused on the management of GI bleed and the role of endoscopy services. ${ }^{16}$

To conclude, research and innovations in the area of health care delivery is the need of the hour. Training sessions for the treating team and providing them with management protocols in an accessible format are likely to be the most cost effective interventions in improving health care delivery. The Indian health education system has focused on creating health care experts, which it has undoubtedly done. It is now for these health care experts, to put their heads together to improve health care delivery in India and prioritize this aspect of medical care.

\section{References}

1. Myer PA, Mannalithara A, Singh G, Singh G, Pasricha PJ,
Ladabaum U. Clinical and economic burden of emergency department visits due to gastrointestinal diseases in the United States. Am J Gastroenterol 2013;108:1496-507.

2. O'Gara PT, Kushner FG, Ascheim DD, et al. American College of Cardiology Foundation/American Heart Association Task Force on Practice Guidelines. 2013 ACCF/AHA guideline for the management of ST-elevation myocardial infarction: a report of the American College of Cardiology Foundation/American Heart Association Task Force on Practice Guidelines. Circulation. 2013;127:e362-425.

3. Jauch EC, Saver JL, Adams HP Jr, et al. American Heart Association Stroke Council; Council on Cardiovascular Nursing; Council on Peripheral Vascular Disease; Council on Clinical Cardiology. Guidelines for the early management of patients with acute ischemic stroke: a guideline for healthcare professionals from the American Heart Association/American Stroke Association. Stroke. 2013;44:870-947.

4. ASGE Ensuring Safety in the Gastrointestinal Endoscopy Unit Task Force, Calderwood AH, Chapman FJ, Cohen J, Cohen LB, Collins J, Day LW, et al. Guidelines for safety in the gastrointestinal endoscopy unit. Gastrointest Endosc. 2014;79:363-72.

5. Laine L, Jensen DM. Management of patients with ulcer bleeding. Am J Gastroenterol. 2012;107:345-60.

6. Cohen J, Pike IM. Defining and measuring quality in endoscopy. Gastrointest Endosc. 2015;81:1-2. 
7. Bulletin of the World Health Organization. India tries to break cycle of health-care debt. http://www.who.int/bulletin/volumes/ 88/7/10-020710/en/.

8. Rao M, Rao KD, Kumar AK, Chatterjee M, Sundararaman T. Human resources for health in India. Lancet. 2011;377:587-98.

9. Balarajan Y, Selvaraj S, Subramanian SV. Health care and equity in India. Lancet. 2011;377:505-15.

10. Grol R, Grimshaw J. From best evidence to best practice: effective implementation of change in patients' care. Lancet. 2003;362:1225-30.

11. Davis D, Evans M, Jadad A, Perrier L, et al. The case for knowledge translation: shortening the journey from evidence to effect. $B M J$. 2003;327:33-5.

12. Coomarasamy A, Khan KS. What is the evidence that postgraduate teaching in evidence based medicine changes anything? A systematic review. BMJ. 2004;329:1017.

13. http://www.research2guidance.com/500m-people-will-be-usinghealthcare-mobile-applications-in-2015.
14. Shaw CM, Tan SA. Integration of mobile technology in educational materials improves participation: creation of a novel smartphone application for resident education. J Surg Educ. 2015;72:670-3.

15. Bajaj JS, Thacker LR, Heuman DM, Fuchs M, Sterling RK, Sanyal AJ, et al. The Stroop smartphone application is a short and valid method to screen for minimal hepatic encephalopathy. Hepatology. 2013;58:1122-32.

16. VonHoltz LA, Hypolite KA, Carr BG,etal. Use of Mobile Apps: A Patient-centered Approach. Acad Emerg Med. 2015;22:765-8.

17. Atreja A, Khan S, Rogers JD, Otobo E, Patel NP, Ullman T, et al; HealthPROMISE Consortium Group. Impact of the Mobile HealthPROMISE Platform on the Quality of Care and Quality of Life in Patients With Inflammatory Bowel Disease: Study Protocol of a Pragmatic Randomized Controlled Trial. JMIR Res Protoc. 2015;4:e23.

18. http://www.fda.gov/downloads/MedicalDevices/.../ UCM263366.pdf 